\title{
Neural Network Control Methods of Wind Energy Conversion Systems
}

\author{
Li Tai \\ School of Electronic\& Information \\ Jiangsu University of Science and Technology \\ Zhenjiang, China \\ e-mail: teilytl@163.com \\ Hou Xiao-Yan \\ School of Electronic\& Information \\ Jiangsu University of Science and Technology \\ Zhenjiang, China \\ e-mail: 827731008@qq.com \\ Zhao Li \\ ShanDong Water Polytechnic \\ Rizhao, China \\ e-mail:zhaoli_20090909@126.com
}

\author{
Wang Qi-Xiang \\ School of Electronic\& Information \\ Jiangsu University of Science and Technology \\ Zhenjiang, China \\ e-mail: 1181501030@qq.com \\ Xie Dian-Fei \\ School of Electronic\& Information \\ Jiangsu University of Science and Technology \\ Zhenjiang, China \\ e-mail: 394433862@qq.com \\ Liu Hai-Jian \\ School of Electronic\& Information \\ Jiangsu University of Science and Technology \\ Zhenjiang, China \\ e-mail:746811429@qq.com
}

\begin{abstract}
Wind energy has become one of the most widely deployed sources of sustainable energy, using larger wind turbines to convert kinetic energy into electricity has significantly increased, however, the wind turbines control technology is still lagging behind and needs to be improved. The advanced control technology can improve the power grid reliability, maximize energy capture, and ensure safe operation of the wind turbines. Neural network control methods of wind energy conversion systems are given in this paper. Focusing on the maximum wind energy capture control based on neural network methods, shortcomings and deficiencies of the conventional control methods for the wind energy conversion systems are compared. Constant power control and multi-variable control based on neural network methods are given also. Finally, the neural network control methods of wind energy conversion systems are summarized, and a guide to the neural network control of wind energy conversion systems is provided .
\end{abstract}

Keywords-wind energy conversion systems; maximum wind energy capture, neural network; constant power, multivariable control

\section{INTRODUCTION}

As energy consumption rises and environmental pollution becomes increasingly serious, the exploitation and use of renewable energy sources receives more public attention. Wind power industry becomes the fastestdeveloping one among renewable, clean energy sources, playing the increasingly dominant role in renewable energy market. In the future, coming after thermal power and hydropower, wind power will become the 3rd largest conventional power source. The energy provided by wind has been gradually increased. Since the 1990s last century, the global wind power industry has developed rapidly ${ }^{[1]}$, wind energy has been gradually applied to many fields, for example, irrigation, navigation, grinding, city power supply. There are many maximum power point tracking (MPPT) control methods for maximizing the power ${ }^{[2]}$. However, these methods still exist shortcomings.

Active researching on renewable energy resources like wind power significantly increases the energy supply and preserves the environment, forming an integral part of building a harmonious society. The baseline control strategy of wind energy conversion system(WECS), which is the essential part of wind power generations, is that when the current wind velocity is greater than cut-in wind velocity but smaller than the velocity rating, the energy absorbed by the WECS is under the power rating of generator, during which, pitch-controlled system doesn't normally function, with the pitch motor applies MPPT to power output; when the current wind velocity is greater than the velocity rating, the energy absorbed by WECS is beyond the power rating, during which, the pitch motor readjusts the pitch angle to maintain the generator's constant power output ${ }^{[3]}$.Control methods of WECS are multiple, e.g. PID control and fuzzy control, robust control, neural network control, etc. 
Neural networks, also known as multilayer perceptron (MLP), in essence is a simplified model of brain-like information processing mechanism. It is a parallel distributed processor whose operating principle is that a large number of simple processing unit constitutes a non-linear system. Neural network contains a variety of models, such as detector, radial basis function networks $(\mathrm{RBFN})$ and probabilistic neural network(PNN). Main features of neural networks are parallel distributed processing, linear maps, adaptability, integration, selflearning training and the unlimited approximation of nonlinear models and obtainment of optimal value. In recent years, neural networks' applications to the WECS are increasingly common, and a large number of literatures illustrate that neural networks have accessed to a growing amount of fruition in WECS.

This paper has laid particular emphasis on introducing neural networks and its application in WECS, emphasizing control methods of three respects, namely, maximal wind energy capture, constant power(PQ) control and multi-variable optimization.

\section{APPLICATION OF NEURAL NETWORK CONTROL IN WIND ENERGY CONVERSION SYSTEMS}

Paper [4] points out that effective control methods directly improve the efficiency of WECS. In the past, researches which study on WECS have made many achievements, and neural networks control methods have the best prospects. In the field of intelligent control, neural networks has a strong adaptability and learning ability, nonlinear mapping capabilities, robustness and faulttolerance, and WECS is a higher-order, non-linear, strong coupling and multiple-variable, time-varying system, requirements of which are hard to be met by open-loop control or conventional PID control. Thus, a new control method, which applies neural network control methods in the field of intelligent control to $\mathrm{WECS}^{[5]}$ is used by us.

\section{A. Maximum Wind Energy Capture Control based on Neural Network}

Once the maximal wind energy is captured, the power generated by wind turbine remains maximal, and that is MPPT. The theoretical analysis of maximum power point of control is that the non-linearity of wind power output is increased because the wind turbine blades are under the influence of factors such as wind speed and direction. Thus, the wind turbine generator system (WTGS) can work in a variety of output voltage under different wind speed and wind direction. However, only when the value of the output voltage is at a certain point, power output of the wind turbine can reach its highest point. Fast accurate tracking of the wind turbines generate power, and regulating its output current and voltage, making them work at maximum power point, is the key to maximum power control technique.

Paper [6] describes the existing methods of MPPT, such as hill-climbing, fuzzy control and genetic algorithm control. Relative to the direct advertising, maximum power point control method based on neural network, on the other hand, has some advantages, for example, fast response time, small error, strong robustness and quick and accurate regulation, with voltage or current reaches the maximum power point. By using the maximal windenergy tracing principle ${ }^{[7]}$, relationship equation of windgenerated power with wind turbine rotor and wind speed is $\mathrm{p}_{\text {mech }}=12 \rho A v^{3} \mathrm{C}_{\mathrm{p}}$, where $\rho$ is air density, $\mathrm{k}_{\mathrm{g}} / \mathrm{m}^{3} ; v$ is wind speed, $\mathrm{m} / \mathrm{s} ; \mathrm{C}_{\mathrm{p}}$ is wind energy utilization factor; $A$ is wind turbine blade sweep area, $m^{2}, \mathrm{~A}=\pi \mathrm{R}^{2} ; R$ is wind wheel radius.

Rotor power coefficient is used to define levels of power acquired by wind turbine from natural wind. Rotor power coefficient $C_{p}$ is the nonlinear functions with the tip speed ratio $\lambda$ and pitch angle $\beta$, namely, $C_{p}(\lambda, \beta)=c_{1}\left(\frac{c_{2}}{\lambda_{i}}-c_{3} \beta-c_{4}\right) e^{-\frac{c_{5}}{\lambda_{i}}}+c_{6} \lambda \quad$,where, the tip speed ratio $\lambda$ is $\lambda=\frac{2 \pi R n}{v}=\frac{w R}{v} ; \mathrm{w}$ is wind wheel angular velocity, $\frac{1}{\lambda_{i}}=\frac{1}{\lambda+0.08 \beta}-\frac{0.035}{\beta^{3}+1}$.

As we can know from the equations, when the actual wind speed is under rated speed and pitch angle is stated, rotor power coefficient has a maximal point and the tip speed ratios have an optimal value, the greatest wind power will be tracked from there. According to the level of the output power, motor speed and pitch angle, optimal rotary speed can be derived by RBF neural networks' best approximation, and then the maximum power output can be regulated by rotary speed control, maximizing the capture of wind power ${ }^{[8]}$.

\section{B. Constant Power Control based on Neural Network}

Instability of output power of the wind turbine is caused by the randomness of wind speed, the time-varying property of wind turbine parameters and the nonlinearity and time lag of systems. At this point, adjusting the power output of the wind turbine to maintain constant is essential.

Based on the principles of wind energy conversion systems, when the wind speed is above the rated value, there are some common methods for constant power control, for example, traditional PID control is a simply control method using a set of parameters, which is difficult to balance between dynamic and static characteristics. Fuzzy control is not systematic, cannot control complex systems, bringing down accuracy of the system control, and degrading the dynamic quality of the system. However, neural network control has good nonlinear mapping ability which can unlimitedly approximate any nonlinear model, implementing real-time parallel computing and redundant fault-tolerant computing, the control mapping relation between input and output of controlled objects can be obtained through the network training. 
In addition, paper [10] proposes that conventional PID controller cannot solve conflicts between dynamic and static and the conflicts between the trace settings and disturbance restraining. The neural network control is essentially nonlinear approximation control, it cannot eliminate static errors. In order to improve the dynamic performance of variable-speed constant-frequency (VSCF) wind power generation system, the blade pitch angle controller is designed in the constant-power-output operating area, on the basic of the prior knowledge of variable pitch control, we combine the two, using RBF neural network control of PID parameters' real time adjustment. Once real-time, online parameters adjustment controlled by PID has been achieved, PID control with RBF neural network tuning can be formed, and variable pitch controller of WECS can be designed as well. Paper [11] points out that after comparing generator speed value and rated speed, errors produced will be entered to PID controller with RBF neural network tuning, then reference value of optimal pitch angle will be generated according to the algorithms. The error signal, which is obtained by comparing the optimal value and actual pitch angle, will be inputted into the pitch servo system, driving pitch motors to change the blade angle. Then constant power output will be maintained.

\section{Wind Energy Conversion Systems Multivariable Control based on Neural Network}

Optimization issues of WECS is given in paper [12] , which suggests that, for example, how to increase the utilization of wind energy. There are plenty of methods like tracking maximum wind energy, improving power quality, improving reliability of power generation systems. However, there are restraint and contradictory relationship between controlled variables of wind energy conversion systems, and optimizing single one of the variables will affect others. Among the requested control variables, a compromise, which takes each variable into account meets the overall demand, is desired. Thus multivariable optimize control of WECS is put forth.

When WECS runs at the speed under the ratings, the control goal of the systems is to acquire maximum power. Because the available wind energy captured by wind turbines is less than rated output power of the generator, the VPC system does not work. At this point, RBF neural network is adopted to regulate the electromagnetic torque to control the rotor speed of the generator, approximate the best power coefficient curve and achieve the maximum wind energy conversion efficiency. Meanwhile, accurately tracking the best value by tip speed ratio can EFFICIENTLY ACHIEVE THE MAXIMUM CONVERSION OF WIND energy into electricity, acquiring the maximum power.

When WECS runs at the speed over the ratings, the available wind energy captured by wind turbines is more than rated output power of the generator, the power factor hence need to be reduced, and this can be achieved by increasing pitch angle and decreasing tip speed ratio. However, if we take changing pitch angle as the only output of the controller, then using the above pitch-control method will not effectively maintain the stability of power and wind wheel speed. Therefore in high wind speed, rotor speed and power fluctuations and the torque peaks of gear box will be reduced by the use of FNNC's rapid response and accurate regulation of the changing output of generator torque and independent pitch angle, and constant-power control will then be achieved eventually $^{[13-16]}$. The multivariable control of WECS based on data mining is given in paper [17], which combined with neural network has a good control effect, as is shown in Tab .1, the learning ruler include EBPA, MBPM, and OUTSTAR, the training results is given by different errors .

Table I. Different Errors of Neural Network Control

\begin{tabular}{ccccc}
\hline ruler & MAE & STD of MAE & RMAE & STD of RMAE \\
\hline turbine 1 & & & & \\
EBPA & 4.30 & 2.01 & 0.12 & 0.02 \\
MBPM & 3.30 & 1.23 & 0.08 & 0.02 \\
$\begin{array}{c}\text { OUTSTAR } \\
\text { turbine } 2\end{array}$ & 2.25 & 0.95 & 0.05 & 0.01 \\
EBPA & 4.32 & 2.05 & 0.15 & 0.03 \\
MBPM & 3.27 & 1.22 & 0.07 & 0.03 \\
OUTSTAR & 2.33 & 0.93 & 0.06 & 0.02 \\
turbine 3 & & & & \\
EBPA & 4.28 & 1.98 & 0.10 & 0.02 \\
MBPM & 3.21 & 1.03 & 0.08 & 0.01 \\
OUTSTAR & 2.15 & 0.86 & 0.05 & 0.01 \\
\hline
\end{tabular}

\section{CONCLUSION}

This paper describes the application of neural network control methods in WECS mainly from three re spects. The first is maximum wind energy capture control methods based on neural network; the second is constant power control methods based on neural network; the third is multivariable control methods based on neural network. Neural network control methods have strong nonlinear fitting capability, mapping arbitrarily complex nonlinear relationship, and its learning rules are simple for computers to realize, solving the problems of instability of complex WECS. Nevertheless, the nonlinear mapping capabilities of neural network depend on the algorithms of optimal weight adjustment and large network optimization computation requirement. Thus, perfection and improvement in the theory and algorithm of neural network control methods are expected.

\section{ACKNOWLEDGMENT}

This work has been Supported by A Project Funded by the Priority Academic Program Development of Jiangsu Higher Education Institutions (PAPD), A Project Funded by the Dr Foundation of Jiangsu University of Science and Technology under Grant NO.635031303 and A Project Funded by Jiangsu University of Science and Technology 
under Grant NO. 633031304, A Project Funded by the National Natural Science Fund under Grant NO. 51307074, A Project Funded by the Postdoctoral Key Research Fund of Southeast University under Grant NO.1116000185, A Project Funded by the Postdoctoral Science Foundation of Jiangsu Province under Grant NO.1301005B.

\section{REFERENCES}

[1] M. Kittipong, Y. Chitra, L. Weijen and J. R. Liao, An integration of ANN wind power estimation intounit commitment considering the forecasting uncertainty. IEEE Trans. Ind. Appli. vol. 43, Jun. 2007, pp. 1441-1448.

[2] H. Camblong, I. Martinez de Alegria, M. Rodriguez and G. Abad. Experimental evaluation of windturbines maximum power point tracking controllers. Energ. Convers. Manage. vol. 47, Sept. 2006, pp. 2846-2858.

[3] Z. X. Xing, Q. L. Zheng, and X. J. Yao. PID control in adjustablepitch wind turbine system based on BP neural network. Journal of Shenyang University of Technology. vol. 28, Jun. 2006, pp. 681686.

[4] C. M. Hong, W. M. Lin, and F. S. Cheng. Application of fuzzy neural network sliding mode controller for wind driven induction generator system. Proc. 2007 International Conference on Intelligent Systems Applications to Power Systems(ISAP 07), IEEE Press, Nov. 2007, pp. 1-6.

[5] X. H. Liu and S. F. Yu. The application of neural network in the electric control system of major wind turbine generator. Emotorcn. Feb. 2004, pp. 37-38.

[6] Z. C. Ji, Y. Zhu, and T. Meng. MPPT variable gain extremum seeking control method for wind energy conversion system. Electric Machines and Control. vol. 13, Mar. 2009, pp. 414-418.

[7] X. S. Wang, Y. X. Wu, and C. He. Simulation of wind speed estimation for MPPT control. Electric machines and control. vol. 14, Feb. 2010, pp. 20-24.

[8] T. Li, Y.X. Shen and Z.C. Ji. Research on A Novel MPPT Control Method for Variable-Speed Wind Power Systems. Research
Journal of Applied Sciences, Engineering and Technology, vol. 4, Aug. 2012, pp. 2712-2715.

[9] M Hoa, D. Nguyen, and N. Subbaram. Advanced control strategies for wind energy systems: An overview. Proc. 2011 IEEE/PES Power Systems Conference and Exposition (PSCE 07), IEEE Press, Mar. 2010, pp. 1-8.

[10] X. F. Song and LIU Jun. HUANG Ge. Variable pitch control of wind power generation based on RBF neural network tuning PID control. Power System and Clean Energy. vol. 25, Apr. 2009, pp. 49-53.

[11] Y.D. Song, B. Dhinakaran, and X. Y. Bao. Variable speed control of wind turbines using nonlinear and adaptive algorithms. Journal of Wind Engineering and Industrial Aerodynamics, vol. 85, Dec. 2000, pp. 293-308.

[12] Y. L. Li, Z. U. Yun and Z. C. Ji. Overview for optimal Control strategies of wind energy conversation system. Small \& Special Electrical Machines, Feb. 2009, pp. 59-63.

[13] L. L. Xu and Z. C. Ji. Data-Base Optimal Control for Wind Energy Conversion System. Journal of Nanjing University of aeronautics \& Astronautics, vol. 44, Jan. 2012, pp. 129-133.

[14] T. Li and Z. C. Ji. Intelligent Inverse Control to Maximum Power Point Tracking Control Strategy of Wind Energy Conversion System. Proc. 2011 Chinese Control and Decision Conference (CCDC 11), IEEE Press, 2011, pp. 970-974.

[15] Y. D. Chen, Y. L. Yang, and L. Q. Wang .Maximum power poin tracking technology and simulation analysis for wind power generation. High voltage engineering. vol. 36, May. 2010, pp. 1322-1326.

[16] Y. L. He, S. Huang, and D. X. Su, Jun Li, H. J. Ren, and J. Liu. Multivariable pitch control strategy for variable speed wind turbine. Power System Protection and Control. vol. 39, Aug. 2011, pp. 3337.

[17] T. Li and Z. C. Ji. Data Driven Control for Wind Energy Conversion System Output Power based on Neural Network Compensator. Journal of Control Science and Engineering, vol. 2012, 2012, pp. 1-8. 